\title{
The Role of Routine Laboratory Studies and Neuroimaging in the Diagnosis of Dementia: A Clinicopathological Study
}

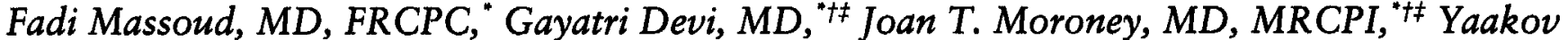 \\ Stern, PhD, ${ }^{*} \neq \S$ Arlene Lawton, $R N,{ }^{* \dagger}$ Karen Bell, MD, ${ }^{* \neq}$ Karen Marder, MD, MPH, ${ }^{* \dagger}$ and \\ Richard Mayeux, MD, MSc ${ }^{* t \$ 5 \pi}$
}

OBJECTIVE: To determine the neuropathological diagnoses of longitudinally followed patients with potentially reversible causes of dementia and to examine the results of the "dementia work-up," especially neuroimaging, by comparison with the pathological diagnosis.

DESIGN: A neuropathologic series of 61 consecutive patients, with review of clinical, laboratory, neuroimaging, and pathological results.

RESULTS: Of the 61 patients, forty-eight (79\%) had a clinical diagnosis of probable or possible Alzheimer's disease (AD). Compared with the pathological diagnosis, the sensitivity and specificity of the clinical diagnosis of AD were $96 \%$ and $79 \%$, respectively. Of the 61 patients, 9 had abnormal laboratory tests, the correction of which did not improve the subsequent course. These patients were found to have $\mathrm{AD}^{8}$ and frontotemporal dementia ${ }^{1}$ on pathology. In two patients, neuroimaging was helpful in the clinical diagnoses of frontotemporal dementia and progressive supranuclear palsy (PSP). Neuroimaging revealed cerebrovascular disease in 18 patients, only two of whom were suspected clinically. Pathology confirmed AD in 17 and PSP in 1 of these patients. Sensitivity and specificity for the clinical diagnosis of cerebrovascular disease in comparison with pathology were $6 \%$ and $98 \%$, respectively. With the added information from neuroimaging, that sensitivity increased to $59 \%$ and specificity decreased to $81 \%$.

CONCLUSIONS: All cases with abnormal laboratory or neuroimaging results had $\mathrm{AD}$ or some other neurodegenerative disease on pathology. The "dementia work-up" did not reveal any reversible causes for dementia in this group of

From the "Gertrude H. Sergievsky Center, the TTaub Institure for Research on Alzheimer's Disease and the Aging Brain, the $¥$ Department of Neurology, and the SDepartment of Psychiarry, Columbia University College of Physicians and Surgeons and Columbia-Presbyterian Medical Center, New York, New York; and the IDivision of Epidemiology, School of Public Health at Columbia University, New York, New York.

Support was provided by grants AG07232, AG08702, and RR00645, and K08 NS02051 from the National Institutes of Health, Bethesda, Maryland; by the Charles S. Robertson Memorial Gift for Alzheimer's Disease Research from the Banbury Fund, Cold Spring Harbor, New York; and by a grant from the Blanchette Hooker Rockefeller Fund, New York, New York. Dr. Massoud is supported by a grant from the McLaughlin Foundation, Ontario, Canada.

This work was presented in part at the American Geriatrics Society meeting held in Philadelphia, Pennyslvania, May 1999.

Address correspondence to Dr. Richard Mayeux, MD, MSc, G.H. Sergievsky Center, 630 West 168th Street, New York, NY 10032. patients. Neuroimaging may have a role, especially in the diagnosis of possible AD with concomitant cerebrovascular disease. J Am Geriatr Soc 48:1204-1210, 2000.

Key words: dementia; Alzheimer's disease; laboratory studies; neuroimaging

$\mathrm{T}$ he widely used work-up for the evaluation of dementia stems from early reports of missed reversible cases for cognitive syndromes, ${ }^{1-3}$ published before the development of standardized rigorous clinical criteria for the diagnosis of dementia. $^{4-6}$ Since then, two large meta-analyses ${ }^{7,8}$ of over 3000 patients have found that between $8 \%$ and $9.3 \%$ of patients had partially reversible disease and only $1.5 \%$ to $3 \%$ had fully reversible dementia. The main causes of partially or completely reversible dementia were medications, depression, and metabolic disorders (especially thyroid dysfunction). Several methodological problems were noted by the authors of those meta-analyses, mainly the limited follow-up periods and the lack of objective criteria for improvement of the cognitive disorders. Furthermore, vascular dementia and concomitant Alzheimer's disease (AD) and cerebrovascular disease (also referred to as "mixed dementia") were not considered in those analyses because they were deemed irreversible by the authors. However, several recent studies have emphasized the importance of vascular lesions in the expression and severity of dementia in $\mathrm{AD} ., 10$ Identifying such lesions may thus hold some promise in terms of tertiary prevention (control of vascular risk factors) by delaying progression or severity of illness. ${ }^{11,12}$

For editorial comment, see p 1345

Some contend that the low frequency of "reversible dementias" argues against extensive investigation of all patients with cognitive complaints. ${ }^{8}$ There have been conflicting guidelines concerning the assessment of dementia. ${ }^{13-16}$ Most of the disagreement concerns the role of neuroimaging in the work-up of dementia. Although most authorities advocate a neuroimaging procedure in a selected group of demented patients, $7,13-15,17-20$ some still recommend it routinely for all patients. ${ }^{16,21}$ Two recent studies ${ }^{20,22}$ evaluated the clinical role of published recommendations for the assessment of dementia. They showed that, by applying certain clinical 
indicators, a significant number of neuroimaging studies is avoided with relatively little meaningful information missed. In both studies, cerebrovascular disease on brain imaging resulted in changes in clinical diagnoses. Brain imaging also influenced the management of vascular risk factors and cerebrovascular disease. 22

The objectives of our clinicopathological study were threefold: (1) to determine the neuropathological diagnoses of longitudinally followed patients with potentially reversible causes of dementia, (2) to examine the results of the dementia work-up by comparison with the pathological diagnosis, and (3) to specifically assess the role of neuroimaging in the diagnosis of concomitant cerebrovascular disease.

\section{METHODS}

\section{Study Population}

The study population consisted of 61 patients evaluated at the Columbia University Alzheimer's Disease Research Center (ADRC), a tertiary care facility for patients with cognitive complaints.

\section{Clinical Diagnosis}

The diagnosis of dementia was based on the criteria of the Diagnostic and Statistical Manual, Revised Third Edition (DSM-III-R). ${ }^{5} \mathrm{AD}$ was diagnosed according to the National Institute of Neurological and Communicative Disorders and Stroke-Alzheimer's Disease and Related Disorders Association (NINCDS-ADRDA) criteria . 4 The diagnosis of vascular dementia was based on the National Institute of Neurological Disorders and Stroke and the Association Internationale pour la Recherche et l'Enseignement en Neurosciences (NINDSAIREN) criteria. ${ }^{23}$ The presence of concomitant AD with cerebrovascular disease on clinical evaluation or neuroimaging was classified as possible $\mathrm{AD}$. The term "mixed dementia" will also be used hereafter as a synonym of the NINCDSADRDA category of possible $\mathrm{AD}$ with cerebrovascular disease.

\section{Clinical Evaluation}

The clinical evaluation of memory impairment included a structured neurological, functional, and psychiatric examination, neuropsychological testing, a series of laboratory tests (complete blood count, serum electrolytes, liver and renal function tests, serum B12, folate, VDRL, thyroid function tests) and brain imaging (computerized axial tomography scan (CT) or magnetic resonance imaging scans (MRI) of the brain). Results of the laboratory tests and imaging procedures were available for most patients for this analysis. The results of neuroimaging studies were considered as interpreted by the original neuroradiologist. Infarcts were defined as focal cortical or noncortical lesions in a recognized vascular territory, and white matter disease was defined as periventricular or deep white matter hypodensities on brain CT or MRI. Missing data were mostly due to the unavailability of the results for patients whose initial evaluation was carried out in an outside institution.

\section{Autopsy Consent and Neuropathological Diagnosis}

All patients and their families were given information on neuropathological examination and gave verbal consent if they wished to participate in the free autopsy program offered through ADRC. Informed consent was obtained from next of kin upon death for all patients. Neuropathological examinations were performed at the Columbia Presbyterian Medical Center (except for two cases). In all but one case evaluated at Columbia, the left half of the cerebrum was quick frozen, and the right half was fixed in formalin for gross and microscopic evaluation. In the two other cases, the left half of the cerebrum was fixed for microscopic study. Pathological reports were reviewed to insure that the relevant hemibrain (i.e., the hemibrain showing cerebrovascular disease on imaging) was examined. In one case, the hemibrain opposite to the one with neuroimaging findings was examined. The diagnosis was based either on the Consortium to Establish a Registry for Alzheimer's Disease (CERAD) criteria ${ }^{24}$ or the Khatchaturian criteria ${ }^{25}$ for AD. Diagnoses of other dementias were made using standard published clinical and pathological criteria. $^{26-29}$ The presence of concomitant AD and cerebrovascular pathology was classified as possible $\mathrm{AD}$. The term "mixed dementia" will also be used to refer to this pathological entity.

\section{Statistical Analyses}

Means, standard deviations, and group percentages were used as frequency measures for the demographic and clinical characteristics of the study population. Clinical diagnosis of $\mathrm{AD}$ was compared with the neuropathological diagnosis. For purposes of this analysis, clinical and pathological diagnoses were classified as either $A D$ or non-AD. Sensitivity of the clinical diagnosis was defined as the number of patients with the clinical diagnosis of $\mathrm{AD}$ who also met the pathological criteria of $\mathrm{AD}$ ("true positives") divided by the total number of patients with a definite, pathological diagnosis of AD. Specificity was defined as the number of patients with a clinical diagnosis other than $\mathrm{AD}$ who also had a pathological diagnosis other than $\mathrm{AD}$ ("true negatives") divided by the total number of patients with a pathological diagnosis other than $\mathrm{AD}$. The sensitivity and specificity of the initial (i.e., at the first clinic visit) clinical and neuroimaging diagnoses of cerebrovascular disease were determined by comparing them with the definite neuropathological diagnosis considered as the gold standard in the same manner described for AD.

\section{RESULTS}

\section{Demographic Characteristics}

Demographic and clinical characteristics of the study population are presented in Table 1.

\section{Clinical and Pathological Diagnoses (Table 2)}

Of the 61 patients, $41(67 \%)$ had a clinical diagnosis of probable $\mathrm{AD}, 7(\mathbf{1 2} \%)$ had a diagnosis of possible $\mathrm{AD}, 10$ $(16 \%)$ had another diagnosis (chromosome 17-associated familial dementia, ${ }^{2}$ frontal lobe dementia, ${ }^{2}$ CreutzfeldtJakob dementia, ${ }^{2}$ adult polyglucosan disease, ${ }^{1}$ Parkinson's disease associated dementia, ${ }^{1}$ and dementia of unknown etiology ${ }^{2}$ ), and $3(5 \%)$ did not meet criteria for dementia. The sensitivity of the clinical diagnosis of $\mathrm{AD}$ was $96 \%$ and the specificity was $79 \%$. Clinical and pathological diagnoses differed in five patients. Three patients with a clinical diagnosis of $\mathrm{AD}$ (false positives) had pathological diagnoses of pure Lewy body disease, subcortical gliosis, and multiple sclerosis. Two patients with clinically diagnosed dementia of "unknown etiology" had $\mathrm{AD}$ on pathological examination (false negatives). 
Table 1. Clinical and Demographic Characteristics of the Study Population

\begin{tabular}{lc}
\multicolumn{1}{c}{ Characteristics } & Frequency \\
\hline Gender & \\
Male, $n(\%)$ & $36(59)$ \\
Female, $n(\%)$ & $25(41)$ \\
Ethnic group & \\
White, $n$ (\%) & $50(82)$ \\
Black, $n$ (\%) & $5(8)$ \\
Hispanic, $n(\%)$ & $5(8)$ \\
Other, $n(\%)$ & $1(2)$ \\
Age at entry, years (SD) & $69(11)$ \\
Age at death, years (SD) & $74(11)$ \\
Education, years (SD) & $14(4)$ \\
Duration in study, years (SD) & $4(3)$ \\
Mean CDR at last clinical evaluation (SD) & $1.74(1.9)$ \\
Clinical diagnosis (\%) & \\
Probable AD & $41(67)$ \\
Possible AD & $7(12)$ \\
Other & $10(16)$ \\
No dementia & $3(5)$ \\
\hline
\end{tabular}

$\mathrm{SD}=$ standard deviation; $\mathrm{CDR}=$ Clinical Dementia Rating Scale $\left({ }^{70}\right) ; \mathrm{AD}=$ Alzheimer's disease.

\section{Laboratory Results and Clinical Course}

All patients had normal basic laboratory test results including complete blood count and chemistry profile. Results of the metabolic work-up (thyroid function tests, vita$\operatorname{min~B12}$ and folate levels) were available for $56(92 \%)$ of the 61 patients. None of the patients had abnormal folate levels. Two of the 56 patients had low vitamin B12 levels. They were clinically thought to have possible $\mathrm{AD}$, and their cognitive function did not improve with vitamin B12 replacement therapy and they both had AD on pathology. Five of the 56 patients had abnormal thyroid function tests (three were hypothyroid and two were hyperthyroid with thyroid replacement therapy), the treatment of which did not lead to any improvement in cognition. Clinically, these five patients were classified as possible $\mathrm{AD}$ (four cases) and frontotemporal dementia (one case). They were found to have $\mathrm{AD}$ (four cases) and frontotemporal dementia (one case) on pathology. Serum screening for neurosyphilis (VDRL) was positive in two instances, one of whom had been treated for syphilis in the past. In the other patient, it was ruled out by cerebrospinal fluid examination. Possible AD was suspected clinically and confirmed on neuropathological examination in both cases.

\section{Results of Neuroimaging}

Results of initial neuroimaging procedures were available for 60 of the 61 patients (98\%). Of those, 19 had MRIs, 23 had CT scans, and 18 had both. Imaging revealed structural abnormalities supporting the clinical diagnosis in two non-AD patients: it showed brain stem atrophy (with MRI) in a patient with progressive supranuclear palsy, and frontotemporal atrophy (with CT and MRI) in a patient with frontotemporal dementia. Infarcts were demonstrated in 15 patients ( 13 with MRI, 1 with both CT and MRI, and 1 with CT), only two of whom were suspected clinically (four corti- cal, six subcortical, two mixed cortico-subcortical, two brain stem, and one cerebellar). Probable AD was clinically diagnosed in 13 patients, and possible $A D$ with stroke in the remaining 2 patients.

Sensitivity and specificity of the clinical diagnosis of stroke in this sample were $8 \%$ and $98 \%$, respectively, when compared with neuropathology. With the added information provided by neuroimaging, sensitivity increased to $54 \%$ and specificity decreased to $83 \%$ (Table 3 ). When all cerebrovascular abnormalities were considered simultaneously (infarcts and white matter disease), 18 cases were revealed by neuroimaging (14 with MRI, 2 with both CT and MRI, and 2 with CT), only 2 of which were suspected clinically. Sensitivity and specificity of the clinical diagnosis of all cerebrovascular disease were $6 \%$ and $98 \%$, respectively, when compared with findings on neuropathology. The information provided by neuroimaging increased sensitivity to $59 \%$ and decreased specificity to $81 \%$ (Table 4 ). Three patients in our study with a clinical diagnosis of probable or possible $\mathrm{AD}$ had isolated white matter disease on neuroimaging. Two out of these three patients had cerebrovascular changes on pathology (one had infarcts and one had severe arteriosclerosis). In 12 patients, cerebral infarcts were demonstrated on pathology, whereas none were suspected clinically (on history and physical examination) (Table 3). The average time between the clinical and pathological evaluations was 5 years (standard deviation $(\mathrm{SD})=3$ ). Review of the medical charts of these patients revealed a history of stroke (after the initial clinical evaluation) in only one case. Interestingly, the neuropathological evaluation revealed microscopic infarcts in 6 of these 12 patients. In seven patients, cerebrovascular disease was demonstrated on pathology, although none was shown on neuroimaging (Table 4). In these patients, the average time between neuroimaging and pathological evaluations was 6 years $(S D=4)$. Three of these seven patients had repeat neuroimaging (one for transient ischemic attack-like symptoms, one for increased confusion and myoclonic jerks, and one for unclear reasons), on average, 1 year before death, and no cerebrovascular disease was shown in any case. Eight patients had evidence of cerebrovascular disease on neuroimaging but not on pathological examination. Pathological reports were reviewed to insure that the relevant hemibrain (i.e., the hemibrain showing cerebrovascular disease on imaging) was examined. In seven of the eight cases, the hemibrain with the changes described on imaging was examined pathologically. In one case, neuroimaging showed a lacunar stroke in the right hemibrain while the left hemibrain was fixed for microscopic examination.

\section{DISCUSSION}

The metabolic work-up including thyroid function tests and vitamin B12 and folate levels did not reveal any reversible causes for dementia in our cohort. The five patients who had abnormal thyroid function tests and the two patients with vitamin B12 deficiency all had a primary neuropathological diagnosis of a degenerative dementing disorder (AD in six, and frontotemporal dementia in one). The findings of this study of a highly selected group of patients cannot be used to determine the actual prevalence of reversible dementia. However, they seem to lend some support to previous studies reporting a relative scarcity of reversible metabolic causes in patients presenting with memory complaints at a tertiary medical center. ${ }^{7,8}$ These findings also support the concept of 
Table 2. Correlation Between Clinical and Neuropathological Diagnoses

\begin{tabular}{|c|c|c|c|c|c|}
\hline \multirow[b]{3}{*}{ Clinical Diagnosis } & \multicolumn{4}{|c|}{ Neuropathological Diagnoses } & \multirow[b]{3}{*}{ Total } \\
\hline & \multicolumn{2}{|c|}{$A D$} & \multirow[b]{2}{*}{ VD } & \multirow[b]{2}{*}{ Other } & \\
\hline & Definite AD & Mixed $A D$ & & & \\
\hline \multicolumn{6}{|l|}{$A D^{*}$} \\
\hline Probable AD & 25 & 14 & 0 & 2 & 41 \\
\hline Possible AD & 2 & 4 & 0 & 1 & 7 \\
\hline VD & $\overline{0}$ & 0 & 0 & 0 & 0 \\
\hline Other & 2 & 0 & 0 & 11 & 13 \\
\hline Total & 29 & 18 & 0 & 14 & 61 \\
\hline
\end{tabular}

- Sensitivity of the clinical diagnosis of AD was $96 \%$ (45/47). Specificity of the clinical diagnosis of AD was 79\% (11/14).

$\mathrm{AD}=$ Alzheimer's disease; $\mathrm{VD}=$ vascular dementia.

Table 3. Sensitivity and Specificity of Clinical and Neuroimaging Diagnosis of Cerebral Infarction

\begin{tabular}{lcc}
\hline & \multicolumn{2}{c}{$\begin{array}{c}\text { Neuropathological } \\
\text { Diagnosis }\end{array}$} \\
\cline { 2 - 3 } & Infarcts & No Infarcts \\
\hline Clinical Diagnosis* & 1 & 1 \\
$\quad$ Stroke & 12 & 46 \\
No stroke & 13 & 47 \\
$\quad$ Total & & \\
Neuroimaging Diagnosis ${ }^{t}$ & 7 & 8 \\
$\quad$ Stroke & 6 & 39 \\
No stroke & 13 & 47 \\
Total &
\end{tabular}

- Sensitivity of clinical diagnosis $=1 / 13=8 \%$. Specificity of clinical diagnosis $=$ $46 / 47=98 \%$.

${ }^{t}$ Sensitivity of neuroimaging diagnosis $=7 / 13=54 \%$. Specificity of neuroimaging diagnosis $=39 / 47=83 \%$.

"modifiable" dementia introduced by some authors to describe patients with an underlying irreversible neurodegenerative disorder who may temporarily be ameliorated or stabilized by the treatment of a medical condition or metabolic disorder but who, when followed for a longer period of time, gradually and relentlessly deteriorate. ${ }^{30} \mathrm{~A}$ study by Larson et al. seems to support this hypothesis. ${ }^{18}$ In this study, 13 patients with reversed dementia were followed for more than 2 years after treatment of the alleged cause. After initial improvement, $62 \%$ of patients (three of four patients with hypothyroidism, four of six patients with medical intoxication, and one patient with subdural hematoma) progressively deteriorated and had a course consistent with AD. Neuropathological examination on two of these patients confirmed the diagnosis of AD. Modifying aggravating factors would be expected to yield the best results in the earliest stages of dementia. To our knowledge, no other clinicopathological series studying patients with "potentially reversible" dementia exist.

Neuroimaging did not reveal any reversible structural causes for dementia in this cohort of patients that are in agreement with previous studies. ${ }^{78}$ Neuroimaging supported the clinical diagnosis in one patient with frontotemporal dementia (frontal lobe atrophy), and one patient with progressive supranuclear palsy (brain stem atrophy).
Table 4. Sensitivity and Specificity of Clinical and Neuroimaging Diagnosis of All Cerebrovascular Disease

\begin{tabular}{lcc}
\hline & \multicolumn{2}{c}{ Neuropathological Diagnosis } \\
\cline { 2 - 3 } & $\begin{array}{c}\text { Cerebrovascular } \\
\text { Disease }\end{array}$ & $\begin{array}{c}\text { Norebrovascular } \\
\text { Disease }\end{array}$ \\
\hline $\begin{array}{l}\text { Clinical Diagnosis* } \\
\text { Cerebrovascular } \\
\text { disease }\end{array}$ & 1 & 1 \\
$\begin{array}{l}\text { No cerebrovascular } \\
\text { disease } \\
\text { Total }\end{array}$ & 16 & 42 \\
$\begin{array}{l}\text { Neuroimaging Diagnosis }{ }^{t} \\
\text { Cerebrovascular } \\
\text { disease } \\
\begin{array}{l}\text { No cerebrovascular } \\
\text { disease }\end{array}\end{array}$ & 17 & 43 \\
$\quad$ Total & 7 & 85 \\
\hline
\end{tabular}

* Sensitivity of clinical diagnosis $=1 / 17=6 \%$. Specificity of clinical diagnosis $=$ $42 / 43=98 \%$.

${ }^{t}$ Sensitivity of neuroimaging diagnosis $=10 / 17=59 \%$. Specificity of neuroim. aging diagnosis $=35 / 43=81 \%$.

Neuroimaging did improve the sensitivity of the clinical diagnosis of $\mathrm{AD}$ with concomitant cerebrovascular disease often referred to as mixed dementia. ${ }^{31}$ The finding of low clinical sensitivity for the clinical diagnosis of stroke (or possible $\mathrm{AD}$ with stroke) is somehow disturbing. However, on closer examination of the pathological findings, 6 out of the 12 patients had microinfarcts suggesting mild disease that may explain the lack of a history of stroke. Mixed dementia is usually found in patients with vascular risk factors ${ }^{32}$ and is difficult to diagnose clinically without the use of neuroimaging. ${ }^{22}$ It is often misdiagnosed as $A D$ or vascular dementia. ${ }^{33}$ In a group of patients from a memory disorders clinic, memory was shown to progress differently in patients with $A D$, mixed dementia, and vascular dementia. ${ }^{34}$ Memory was more impaired in the mild stages of $\mathrm{AD}$, with mixed and vascular dementias catching up in the more advanced stages of impairment, suggesting a potential for intervention early on in the progression of the disease. One study has shown that mixed dementia has a higher mortality than AD (but lower than vascular dementia). ${ }^{35}$ Furthermore, clinicopatho- 
logical studies suggest more severe clinical dementia in patients with mixed $\mathrm{AD}$ in comparison with patients with "pure" $\mathrm{AD}, 9,10 \mathrm{By}$ extrapolating to the results of the few intervention trials carried out in vascular dementia, ${ }^{11,12,36-38}$ one could hypothesize that control of vascular risk factors and antiplatelet treatment may also delay progression of mixed dementia. Even a modest delay could reduce the financial and emotional burden imposed by the functional limitations of this disease. ${ }^{39}$ Unfortunately, there are no trials that have evaluated interventions aimed at slowing the progression of mixed dementia. The clinical relevance of periventricular white matter lesions (PVWML) in association with $\mathrm{AD}$ is still controversial. Three patients in our study with a clinical diagnosis of probable AD had PVWML with no infarcts on brain imaging. Even though the original interpretation of neuroimaging studies was considered and no objective scale to rate PVWML was used (which may potentially have underestimated the prevalence of these findings), sensitivity and specificity for detection of cerebrovascular disease improved when the imaging results from these patients were considered. Some controversy surrounds what underlies these findings on neuroimaging. Clinically, they are usually associated with vascular risk factors, ${ }^{40}$ whereas pathology usually reveals hyaline fibrosis of vessels and perivascular and diffuse demyelination suggestive of an ischemic pathophysi-

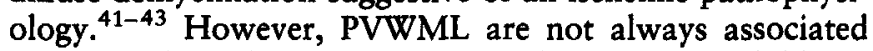
with vascular risk factors, and pathology may reveal dilated perivascular spaces, spongiosis, or Wallerian degeneration suggesting a nonischemic etiology. ${ }^{44-46}$ Two out of three patients with isolated PVWML on imaging had cerebrovascular changes on pathology (one had infarcts, and one had severe arteriosclerosis), suggesting that this finding may be at least a marker for cerebrovascular disease if not a result of it.

Several studies have shown an association between PVWML and severity of cognitive function in AD. ${ }^{47-52}$ This association was significant only in the mild stages of $A D$ in one study, ${ }^{53}$ suggesting, once more, that a preventive intervention at this stage might delay progression of the disease. One study ${ }^{54}$ showed that PVWML on brain CT scans (but not MRI) correlated with severity of dementia in AD. Other studies have refuted this association. ${ }^{55-60}$ The clinical course of $A D$ does not seem to be influenced by the presence of PVWML. ${ }^{61}$ Periventricular white matter lesions on CT scan (but not MRI) were found to predict neurological focal signs (ataxia, asymetric deep tendon reflexes, focal motor deficits, abnormal plantar reflexes) and abnormalities on electroencephalogram at 12 months of follow-up in a group of patients with $\mathrm{AD}$ suggesting an association with cerebrovascular disease. ${ }^{62}$ Deep white matter lesions, especially in the frontal lobes, are also associated with depressive symptomatology. ${ }^{63,64}$ Finally, PVWML have recently been associated with gait disturbances and disequilibrium in older populations with $^{65}$ or without ${ }^{6,67}$ cognitive impairment. When all these studies are considered, clinical evidence seems to suggest an association between cerebrovascular disease and PVWML on neuroimaging. However, the current literature does not allow the conclusion that these lesions are truly the result of cerebrovascular disease. In that matter, the NINDS-AIREN group has concluded in their guidelines for the diagnosis of vascular dementia that "PVWML can be considered evidence for cerebrovascular disease; however, to be significant, these changes must be diffuse, and extensive, and characterized by irregular periventricular hyperintensities on T1 and T2 MRI extending to the deep white matter but sparing the areas thought to be protected from perfusion insufficiency."23

This study has several limitations. We did not have complete laboratory and imaging information on all patients even though we had definite pathological diagnosis on all of them. Ours represents a somewhat selected population of demented patients: subjects with truly reversible causes may not have been followed-up for a long period of time, and may have had a lesser chance of agreeing to autopsy. Some of these patients may also have been screened and treated by their primary care physicians without referral to a memory disorders clinic. Hence, even if clinical reports and metaanalyses $^{7,8}$ have repeatedly shown that reversible causes are exceedingly rare, a community-based study might have revealed different findings. Similarly, a study carried out in a community-based or primary care setting might have shown very different findings in terms of cerebrovascular findings. ${ }^{68,69}$

The clinicopathological correlations in this study revealed some discrepancies that deserve further discussion. In seven cases, the cerebrovascular findings on imaging were not confirmed on pathology. This suggests that neuroimaging may be more sensitive in detecting mild cerebrovascular disease that might be otherwise missed by the neuropathological evaluation of successive brain slices or, less likely, an artifactual change on neuroimaging not substantiated by neuropathology. Comparing results on neuroimaging with neuropathological findings several years later also has its caveats. In the six cases with infarcts on pathology that were not reported on imaging, the vascular events may have occurred later on in the progression of the disease, underestimating the sensitivity of neuroimaging in comparison with neuropathological examination. Review of the clinical charts of these patients suggests that most of the pathological findings were silent clinically. However, many participants in this study spent their last years in long-term care facilities and may not have been transferred to our hospital (or may have been transferred to another hospital) in the event of an acute neurological episode. Given the fact that MRI is more sensitive than CT scan in revealing ischemic changes, using either CT scan or MRI to determine sensitivity and specificity may have further underestimated the sensitivity of neuroimaging. Finally, inter-rater and intra-rater reliabilities of neuroradiologists could not be assessed retrospectively. Nevertheless, this study has numerous strength, including reliance on rigorous clinical criteria, longitudinal follow-up of patients, and definite neuropathological diagnoses.

In summary, these findings suggest that neuroimaging may have a significant role in the diagnosis of mixed dementia. Future prospective studies with serial neuroimaging and neuropathological confirmation of dementia subtypes are needed to improve clinicians' ability to identify patients with mixed dementia and to characterize those who may benefit from targeted interventions.

\section{REFERENCES}

1. Freemon FR. Evaluation of patients with progressive intellectual deterioration. Arch Neurol 1976;33:658-659.

2. Ron MA, Toone BK, Garralda ME, Lishman WA. Diagnostic accuracy in presenile dementia. Br J Psychiatry 1979;134:161-168.

3. Jellinger K. Pathologic correlates of dementia in Parkinson's disease. Arch Neurol 1987;44:690-691.

4. McKhann G, Drachman D, Folstein M et al. Clinical diagnosis of Alzheimer's disease: Report of the NINCDS-ADRDA Work Group under the aus- 
pices of Department of Health and Human Services Task Force on Alzheimer's Disease. Neurology 1984;34:939-944.

5. American Psychiatric Association Diagnostic and Statistical Manual of Mental Disorders, 3rd Rev Ed. Washington, DC: American Psychiatric Association, 1987.

6. American Psychiatric Association Diagnostic and Statistical Manual of Mental Disorders, 4th Ed. Washington, DC: American Psychiatric Association, 1994.

7. Clarfield AM. The reversible dementias: Do they reverse? Ann Intern Med $1988 ; 109: 476-486$.

8. Weytingh MD, Bossuyt PM, van Crevel $H$. Reversible dementia: More than $10 \%$ or less than $1 \%$ ? A quantitative review. J Neurol 1995;242:466-471.

9. Snowdon DA, Greiner LH, Mortimer JA et al. Brain infarction and the clini cal expression of Alzheimer disease. The Nun Study. JAMA 1997;277:813817.

10. Heyman A, Fillenbaum GG, Welsh-Bohmer KA et al. Cerebral infarcts in patients with autopsy-proven Alzheimer's disease: CERAD, part XVIII. Con sortium to Establish a Registry for Alzheimer's Disease. Neurology 1998;51: 159-162.

11. Meyer JS, Rogers RL, McClintic K et al. Randomized clinical trial of daily aspirin therapy in multi-infarct dementia. A pilot study. J Am Geriatr Soc 1989;37:549-555.

12. Meyer JS, Judd BW, Tawaklna $T$ et al. Improved cognition after control of risk factors for multi-infarct dementia. JAMA 1986;256:2203-2209.

13. Canadian Consensus Conference on the Assessment of Dementia. Assessing dementia: The Canadian consensus. Can Med Assoc J 1991;144:851-853.

14. Report of the Quality Standards Subcommittee of the American Academy of Neurology. Practice parameter for diagnosis and evaluation of dementia (summary statement). Neurology 1994;44:2203-2206.

15. Small GW, Rabins PV, Barry PB et al. Diagnosis and treatment of Alzheimer disease and related disorders. Consensus statement of the American Associa. tion for Geriatric Psychiatry, the Alzheimer's Association, and the American Geriatrics Society. JAMA 1997;278:1363-1371.

16. National Institutes of Health consensus conference. Differential diagnosis of dementing diseases. JAMA 1987;258:3411-3416.

17. Clarfield AM, Larson EB. Should a major imaging procedure (CT or MRI) be required in the workup of dementia? An opposing view. J Fam Pract 1990;31:405-410.

18. Larson EB, Reifler BV, Featherstone HJ, English DR. Dementia in elderly outpatients: A prospective study. Ann Intern Med 1984;100:417-423.

19. Larson EB, Reifler BV, Sumi SM et al. Diagnostic tests in the evaluation of dementia. A prospective study of 200 elderly outpatients. Arch Intern Med 1986;146:1917-1922.

20. Freter S, Bergman $H$, Gold $S$ et al. Prevalence of potentially reversible dementias and actual reversibility in a memory clinic cohort. Can Med Assoc J 1998;159:657-662.

21. Katzman R. Should a major imaging procedure (CT or MRI) be required in the workup of dementia? An affirmative view. J Fam Pract 1990;31:401405.

22. Chui $H$, Zhang $Q$. Evaluation of dementia: A systematic study of the usefulness of the American Academy of Neurology's practice parameters. Neurology 1997;49:925-935.

23. Roman GC, Tatemichi TK, Erkinjuntti T et al. Vascular dementia: Diagnostic criteria for research studies. Report of the NINDS-AIREN International Workshop. Neurology 1993;43:250-260.

24. Mirra SS, Gearing M, Nash F. Neuropathologic assessment of Alzheimer's disease. Neurology 1997;49(suppl):S14-S16.

25. Khachaturian ZS. Diagnosis of Alzheimer's disease. Arch Neurol 1985;42: 1097-1105.

26. Cummings JL, Benson D. Dementia: A Clinical Approach. Woburn, MA: Butterworth, 1992.

27. Joachim CL, Morris JH, Selkoe DJ. Clinically diagnosed Alzheimer's disease: Autopsy results in 150 cases. Ann Neurol 1988;24:50-56.

28. Mirra SS, Heyman A, McKeel D et al. The Consortium to Establish a Registry for Alzheimer's Disease (CERAD). Part II. Standardization of the neuropathologic assessment of Alzheimer's disease. Neurology 1991;41:479-486.

29. McKeith IG, Galasko D, Kosaka K et al. Consensus guidelines for the clinical and pathologic diagnosis of dementia with Lewy bodies (DLB): Report of the Consortium on DLB International Workshop. Neurology 1996;47:11131124.

30. Gordon M, Freedman M. Evaluating dementia: What price testing? Can Med Assoc J 1990;142:1367-1370.

31. Cohen CI, Araujo L, Guerrier R, Henry KA. "Mixed dementia." Adequate or antiquated? A critical review. Am J Geriatr Psychiatry 1997;5:279-283.

32. Corey-Bloom J, Galasko D, Hofstetter CR et al. Clinical features distinguishing large cohorts with possible $\mathrm{AD}$, probable $\mathrm{AD}$, and mixed dementia. J Am Geriatr Soc 1993;41:31-37.
33. Moroney JT, Bagiella E, Desmond DW et al. Meta-analysis of the Hachinski Ischemic Score in pathologically verified dementias. Neurology 1997;49:1096-1105.

34. Bowler JV, Eliasziw M, Steenhuis R et al. Comparative evolution of Alzheimer disease, vascular dementia, and mixed dementia. Arch Neurol 1997;54: 697-703.

35. Barclay LL, Zemcov A, Blass JP, Sansone J. Survival in Alzheimer's disease and vascular dementias. Neurology 1985;35:834-840.

36. Konno S, Meyer JS, Terayama Y et al. Classification, diagnosis and treatment of vascular dementia. Drugs Aging 1997;11:361-373.

37. Nyenhuis DL, Gorelick PB. Vascular dementia: A contemporary review of epidemiology, diagnosis, prevention, and treatment. J Am Geriatr Soc 1998; 46:1437-1448.

38. Forette F, Seux M, Staessen J et al. Prevention of dementia in randomised double-blind placebo-controlled systolic hypertension (Syst-Eur) trial. Lancet 1998;352:1347-1351.

39. Brookmeyer R, Gray S, Kawas C. Projections of Alzheimer's disease in the United States and the public health impact of delaying disease onset. Am J Public Health 1998;88:1337-1342.

40. Blennow $\mathrm{K}, \mathrm{Wallin} A$, Uhlemann $\mathrm{C}$, Gottfries $\mathrm{CG}$. White-matter lesions on CT in Alzheimer patients: Relation to clinical symptomatology and vascular factors. Acta Neurol Scand 1991;83:187-193.

41. Englund E, Brun A, Alling C. White matter changes in dementia of Alzheimer's type. Biochemical and neuropathological correlates. Brain 1988;111: 1425-1439.

42. Chimowitz MI, Estes ML, Furlan AJ, Awad IA. Further observations on the pathology of subcortical lesions identified on magnetic resonance imaging. Arch Neurol 1992;49:747-752.

43. Pantoni L, Garcia JH. Pathogenesis of leukoaraiosis: A review. Stroke 1997; 28:652-659.

44. Munoz DG, Hastak SM, Harper B et al. Pathologic correlates of increased signals of the centrum ovale on magnetic resonance imaging. Arch Neurol 1993;50:492-497.

45. van Gijn J. Leukoaraiosis and vascular dementia. Neurology 1998;51(suppl): S3-S8.

46. Leys D, Pruvo JP, Parent $M$ et al. Could Wallerian degeneration contribute to "leuko-araiosis" in subjects free of any vascular disorder? J Neurol Neurosurg Psychiatry 1991;54:46-50.

47. Diaz JF, Merskey H, Hachinski VC et al. Improved recognition of leukoaraiosis and cognitive impairment in Alzheimer's disease. Arch Neurol 1991;48: 1022-1025.

48. Harrell LE, Duvall E, Folks DG et al. The relationship of high-intensity signals on magnetic resonance images to cognitive and psychiatric state in Alzheimer's disease. Arch Neurol 1991;48:1136-1140.

49. Bondareff W, Raval J, Woo B et al. Magnetic resonance imaging and the severity of dementia in older adults. Arch Gen Psychiatry 1990;47:47-51.

50. Lee A, Yu YL, Tsoi M et al. Subcortical arteriosclerotic encephalopathy-A controlled psychometric study. Clin Neurol Neurosurg 1989;91:235-241.

51 . Schmidt R, Fazekas $\mathrm{F}$, Offenbacher $\mathrm{H}$ et al. Magnetic resonance imaging white matter lesions and cognitive impairment in hypertensive individuals. Arch Neurol 1991;48:417-420.

52. Steingart A, Lau K, Fox A et al. The significance of white matter lucencies on CT scan in relation to cognitive impairment. Can J Neurol Sci 1986;13:383-384.

53. Steingart A, Hachinski VC, Lau $\mathrm{C}$ et al. Cognitive and neurologic findings in demented patients with diffuse white matter lucencies on computed tomographic scan (leuko-araiosis). Arch Neurol 1987;44:36-39.

54. Mirsen TR, Lee DH, Wong CJ et al. Clinical correlates of white-matter changes on magnetic resonance imaging scans of the brain. Arch Neurol 1991;48:1015-1021.

55. Marder K, Richards M, Bello J et al. Clinical correlates of Alzheimer's disease with and without silent radiographic abnormalities. Arch Neurol 1995; 52:146-151.

56. Skoog I, Palmertz B, Andreasson LA. The prevalence of white-matter lesions on computed tomography of the brain in demented and nondemented 85 . year-olds. J Geriatr Psychiatry Neurol 1994;7:169-175.

57. Leys $\mathrm{D}$, Soetaert $\mathrm{G}$, Petit $\mathrm{H}$ et al. Periventricular and white matter magnetic resonance imaging hyperintensities do not differ between Alzheimer's disease and normal aging. Arch Neurol 1990;47:524-527.

58. Lopez OL, Becker JT, Rezek D et al. Neuropsychiatric correlates of cerebral white-matter radiolucencies in probable Alzheimer's disease. Arch Neurol $1992 ; 49: 828-834$.

59. Rao SM, Mittenberg W, Bernardin L et al. Neuropsychological test findings in subjects with leukoaraiosis. Arch Neurol 1989;46:40-44.

60. Hunt AL, Orrison WW, Yeo RA et al. Clinical significance of MRI white matter lesions in the elderly. Neurology 1989;39:1470-1474.

61. de Leon MJ, George AE, Reisberg B et al. Alzheimer's disease: Longitudinal CT studies of ventricular change. AJR Am J Roentgenol 1989;152:1257-1262. 
62. Lopez OL, Becker JT, Jungreis CA et al. Computed tomography - but not magnetic resonance imaging -identified periventricular white-matter lesions predict symptomatic cerebrovascular disease in probable Alzheimer's disease. Arch Neurol 1995;52:659-664.

63. Lopez OL, Becker JT, Reynolds CF et al. Psychiatric correlates of MR deep white matter lesions in probable Alzheimer's disease. J Neuropsychiatry Clin Neurosci 1997;9:246-250.

64. O'Brien J, Desmond P, Ames D et al. A magnetic resonance imaging study of white matter lesions in depression and Alzheimer's disease. Br J Psychiatry 1996;168:477-485.

65. Bennett DA, Gilley DW, Wilson RS et al. Clinical correlates of high signal lesions on magnetic resonance imaging in Alzheimer's disease. J Neurol 1992;239:186-190.
66. Briley DP, Wasay M, Sergent $S$, Thomas $S$, Cerebral white matter changes (leukoaraiosis), stroke, and gait disturbance. J Am Geriatr Soc 1997;45:1434-1438.

67. Kerber KA, Enrietto JA, Jacobson KM, Baloh RW. Disequilibrium in older people: A prospective study, Neurology 1998;51:574-580.

68. Massoud F, Devi G, Stern Y et al. A clinicopathological comparison of a community-based and clinic-based cohorts of patients with dementia. Arch Neurol 1999;56:1368-1373.

69. Nolan KA, Lino MM, Seligmann AW, Blass JP. Absence of vascular dementia in an autopsy series from a dementia clinic. J Am Geriatr Soc 1998;46: 597-604.

70. Morris JC. The Clinical Dementing Rating (CDR): Current version and scoring rules. Neurology 1993;43:2412-2414. 